\title{
A postura do professor e as grandes questões humanas nas práticas educacionais*
}

Valderez F. Fraga**

\begin{abstract}
Resumo
A postura do professor é um desafio, não importa onde ou quando. Problemas a ela inerentes se tornam agudos nos países em desenvolvimento, onde os contrastes vão do urbano às áreas rurais, da pobreza à sociedade tecnologicamente avançada, demandando, simultaneamente, compreensão humana e rápida atualização do conhecimento. A descrição da experiência de duas turmas de educação continuada visando à postura docente discute a disposição dos professoresalunos de enfrentarem grandes questões humanas como a democracia, sem descuidar de conteúdos específicos.

0 objetivo central deste estudo é alertar os educadores sobre a significância de lidar com a postura e o conhecimento. Nesse sentido, vários recursos e abordagens de ensino - além de concorrentes métodos de pesquisa qualitativa - foram previamente escolhidos para que se atingisse, respectivamente, os objetivos de ensino e melhores resultados na pesquisa. Os resultados emergiram em preocupações dos professores-alunos, motivados a assumir uma postura democrática e concretamente dialógica, no sentido da inclusão socioeducacional.
\end{abstract}

As conclusões revelam tanto manifestações singulares de cada turma, sugerindo futuras pesquisas quanto posições intercomplementares e percepções comuns a ambas.

Palavras-chave: postura do professor; educação continuada; democracia.

\section{Abstract}

Teacher's posture is a challenge no matter where or when. Inherent issues become sharp in developing countries, where contrasts go from urban to rural areas and from poverty to technologically advanced societies asking for human understanding and update knowledge simultaneously. Experiences described in two Continuing Education classes, as a means of implementing teachers' posture, discuss dispositions of student-teachers to face big human questions as democracy, without relegating any specific content. This study main objective is to alert educators about the significance of dealing with both, posture and knowledge. Several teaching resources and approaches and also concurrent qualitative research methods were intentionally chosen to reach teaching objectives and to obtain better research results respectively. Results emerge in motivated student-teachers' pre-occupations to assume a democratic and dialogical posture in concrete, toward socio-educational inclusion. Conclusions point out class singular manifestations suggesting future research and also toward some inter- complementary positions and common perceptions of both as well.

Key words: teachers' posture; continuing education; democracy.

Sinceros agradecimentos a: Ana Maria B. Magalhães, Cláudia S. Adler, Patrícia L. Calderón, Sueli N. Cordeiro (mestres - FGV/Ebape), pela contribuição com matérias, sugestões e palestras e a Elenice Gonçalves, ( $\mathrm{Dr}$ - - - UFRJ), pela palestra e debates. A todas, o reconhecimento pelo compartilhamento.

Doutora em Educação pela UFRJ. Professora Convidada da FGV/EBAPE e da UFRJ/IE/ECEX. Endereço: VALORE-RH -Rua Rafael Brotero 91/03 - Centro Guaratinguetá - SP - 12300-300.E-mail: valorerh@ centroin.com.br.

Artigo recebido em setembro de 2006 e aceito para publicação em novembro de 2006. 


\section{Introdução}

A postura do professor é um tema sempre atual e cada vez mais desfiador, devido à complexidade do mundo, ao veloz avanço do conhecimento e aos problemas éticos que conturbam as sociedades. Nesse contexto, a situção docente se agrava nos países em desenvolvimento, como o Brasil, tanto devido ao drama da miséria no terceiro mundo, somado à violência e à corrupção, quanto em decorrência da simultânea exigência de sofisticados padrões tecnológicos.

Essa leitura do panorama atual sugere que investiguemos um recente trabalho em educação continuada, especialmente, seguindo os passos de Morin. O objetivo é responder se há professores, na condição de alunos de E.C., dispostos a uma atitude comprometida com as grandes questões socioeducacionais e éticas relativas à postura docente, apesar do compromisso com o conteúdo específico de cada disciplina.

\section{Contexto e referencial teórico: onde nos encontramos para ensinar e aprender}

Carneiro descreve um espaço onde nos reconheceríamos situados no educar-se e educar nas grandes cidades brasileiras.

[...] se a cidade nasceu entronizada [...] ela alberga, hoje, os sintomas mais preocupantes do declínio civilizacional. É a cidade injusta, a cidade violenta, a cidade socialmente fraturada, a cidade desumana, a cidade descontrolada no crescimento, a cidade ecologicamente sufocante, a cidade sem alma [...] deixou de ser o coração da atividade cívica e comunitária para se transformar, qual mutante degenerescente, no palco de todos os confrontos e desesperos humanos. (CARNEIRO, 2005, p.21)

Essa preocupação com a perda de condições das cidades como contextos favoráveis à educação é um indicativo das frágeis condições de desenvolvimento humano. Carneiro recorre à Paidéia para argumentar que somente o predomínio do cultural, do social e do humano sobre o econômico poderá abrir caminho para a inclusão e afastar o que chamou de "legado de dois séculos de modernidade educativa": a exclusão e a fragmentação do conhecimento, quando a escola inclusiva seria ainda "uma miragem distante" (Idem, 2005, p.22-23).

É nesse espaço antisocial que os esforços educacionais se exaurem, no ir e vir concreto na tensão permanente da cidade, quando muitos dos atingidos são reduzidos à espécie, numa agressão ao indivíduo e numa desagregação da sociedade. O desfiguramento desses três termos - espécie, indivíduo e sociedade -, que Morin (2001d, p.6) aponta como "a cadeia de onde emerge nossa consciência e nosso espírito propriamente humano", solapa a base que ele considera necessária ao ensino "da ética propriamente humana", da ética do futuro, "a antropo-ética". Como agravante, é para esse espaço desordenado dos grandes centros urbanos que os migrantes das áreas rurais dirigem suas esperanças. Isso se deve aos primeiros indícios de melhores condições de trabalho e estudo, a partir de ensinamentos básicos, e da corajosa postura dos chamados professores leigos.

Nesse ponto, a universidade brasileira carece de uma cultura própria que a afaste do "legalismo" confortável e uniformizador que a distancia da possibilidade de atender à pluralidade demandada pela sociedade nacional, que de modo desafiador é singular em sua complexidade multicultural. Um modelo de universidade que acompanhasse a dinâmica da sociedade plural e una, constituinte de uma identidade na diversidade (PAZETO, 2002, p.89, 91, 94), trataria daquela unidade e singularidade que Castoriadis encontra em Morin, numa "estrutura indestrutivelmente solidária" (SILVA, 2001, p.26). Um projeto como o recentíssimo Inclusão Social, da USP, é uma alternativa a ser acompanhada.(BOULOS, 2006).

A expectativa democrática remete à opção pela ética como eixo transversal em todos os níveis de ensino, uma possibilidade de elaboração de opiniões sobre o funcionamento social de "agentes autônomos, respeitosos da liberdade, integridade e direitos dos demais". (GONÇALVES, 2005, p.65). Sobre essas bases se pode esperar uma escola como "espaço privilegiado para a experimentação da vida pública que cada um irá viver" (RODRIGUES, 2002, p.20), uma organização democrática que, no entanto, só será possível se pautada pela 
ética. Em contraste, a falta de liberdade, a exclusão social, o preconceito, o autoritarismo, o individualismo, o egoísmo e o etnocentrismo saem fortalecidos quando falta ética.

A inclusão social sugere práticas de educação permanente da qual "toda a população é alvo e destino", pois a posição de Paul Ricoeur que Jardim enuncia descreve a educação continuada como "abertura a uma sociedade pluralista, onde cada um encontra-se com suas conviçcões". (JARDIM, 2004, p.75). Todavia, o convívio com a realidade faz aparecer uma educação descolada dessas aspirações,. o que leva a concordar com Pazeto que, comentando Duham afirma que "o problema não está no ideal da universidade brasileira" e, sim, "em saber por que não temos a universidade que queremos" (2002, p.89), ao que acrescentamos: por que não temos as cidades que queremos, a sociedade que queremos, por que não somos os cidadãos que queremos ser?

O apelo imediatista de supostas teorias de gestão e o fascínio que exercem - reduzindo-nos tanto a um mero recurso entre os demais como a um capital tão manipulável quanto as maravilhas tecnológicas que a inteligência humana não pára de gerar e de utilizar em nome do sucesso - precisam ser quebrados.. De forma incongruente, o conhecimento exclui de nós mesmos "o poder e conquista da prórpia humanidade" (FRAGA, 2003, p.25), o que se mostra, em especial, pela "hiperespecialização" do ensino.(MORIN, 2001a, p.45).

Apesar dos esforços em projetos sociais, há graves questões à nossa espera, especialmente, porque não temos a educação que queremos. Com o crescimento da última década atendendo a "apenas cerca de $10 \%$ da população escolar em idade de cursar o ensino superior [...] não se pode qualificar o sistema de ensino superior, no Brasil, como de massa, no estrito sentido do termo". Aliás, o modelo "não pode ser considerado inclusivo", nem na educação básica nem na superior (JARDILINO, 2003, p.206), porque, acima da questão das vagas, encontramse a baixa "qualidade" e a escassez de "recursos" o que contribui para disputas tanto entre as áreas sociais quanto no interior do sistema educacional( p.208), deixando um rastro de iniquidades. Nessa linha, Neri (2005) afirma que não basta destinar recursos de orçamentos sociais,pois considera necessário medir os resultados, revelando-se comprometido com esse discurso nas pesquisas que realiza nesse sentido, empregando método eficiente.

A exclusão decorrente dessas lacunas compromete o acesso a bens sociais básicos como o trabalho digno, "exigindo credenciais cartoriais como diplomas" (JARDILINO, 2003,p.204) e privando os jovens de contribuírem para uma construção democrática que substitua estruturas sociais obscuras, ignorando-se que "o ser humano não existe para usufruir do passado, mas para construir o futuro" ao qual outros poderão dar continuidade (RODRIGUES, 2002, p.19). A inclusão na construção do futuro é, portanto, uma missão inerente à ação educacional, passando pela postura do professor diante das grandes questões humanas.

Todos esses problemas que clama por solução no horizonte de nossas consciências, aguardam pela retomada de nós mesmos, para questionar nossa acomodação à condição de meros recursos humanos, perguntando por que não assumimos nosso destino de "agentes intencionais, conscinetes e conseqüentes", reconhecendo-nos responsáveis por omissões e ações que praticamos, no ensino e na gestão ( FRAGA,2003,p.7,p.56).

Muita pesquisa teórica e empírica será necessária para se chegar a uma resposta quanto ao "por que não temos" e ao "por que não somos" já mencionados. Contudo, projetos gerencialistas, contábeis, receita/despesa/lucro, métodos que fracionam o conhecimento, vazio ético e concepções de políticas educacionais opostas à postura de Anísio Teixeira por uma "educação sem objetivos e que a nada se subordine a não ser a graus cada vez mais elevados de educação" (FRAGA, 2003, p.84, 94) excluem, de qualquer iniciativa concreta, a sua essência : a relevância do humano.

Contrariando a "antropo-ética" como "consciência de cidadania planetária" (MORIN, 2001d, p.106), a espécie excluiria o indivíduo competente para transformar a sociedade no sentido da liberdade, da justiça e da eqüidade. Nesses termos, a concepção de democracia teria perdido seu sentido, restando um enorme ruído incompatível com a possibilidade da dialógica plural que aproxima os contrários (Idem, 2001d, p.28, ) com a educação que respeita a diversidade e "instala a dialógica no seio do próprio espírito individual". (MORIN, 1998, p.39). Decorre daí a importância de substituir a preocupação ociosa e alienada, pelapré-ocupação que pensa, planeja, se ocupa e age em educação, no sentido de uma atitude de compartilhamento de problemas e busca de soluções. 
Sem temer o debate sobre as grandes questões humanas, a disposição para "o intercâmbio de idéias produz o enfraquecimento de dogmatismos e intolerâncias, o que resulta no seu próprio crescimento" (MORIN, 1998, p.39).

\section{Metodologia do ensino-aprendizagem e metodologia da pesquisa}

Nesse nosso contexto, misto de pobreza e tecnologia avançada, os desafios no ensino se agigantam porque os contrastes nas condições de vida dos envolvidos podem ser gritantes.

O referencial teórico sugere que há "grandes questões humanas" (SILVA, 2001, p.26) na base dos problemas educacionais, seja nas cidades como no interior, e que a educação continuada é, por princípio, inclusiva. Partindo desse pressuposto, este estudo descreve, analisa e resume os resultados das experiências pedagógicas com duas turmas de alunos-professores cujo foco foi a postura docente diante de grandes questões humanas como cidadania, inclusão social, democracia e ética.

A pesquisa girou em torno das percepções e manifestações desses alunos-professores, em busca de possíveis preocupações quanto à postura docente, singulares e comuns às duas turmas, diante de recursos didáticos $\mathrm{e}$ situações pedagógicas às quais foram expostos nas disciplinas.

\section{Objetivos deste estudo}

\section{Objetivo geral}

Responder à seguinte questão: é perceptível em professores na condição de alunos de educação continuada uma atitude comprometida com grandes questões socioeducacionais, manifestada nas turmas, em relação à postura docente, apesar do compromisso com o conteúdo específico de cada disciplina?

\section{Objetivos específicos}

Responder às seguintes questões:

- É possível perceber preocupações comuns às duas turmas de alunos-professores diante do material didático (entrevista em vídeo, textos, matérias de jornal e filme) e das situações pedagógicas (elaboração e apresentação de trabalhos em grupo, debates e depoimentos escritos) referentes às disciplinas ministradas?

- Quais conceitos-chave discutidos na entrevista de Morin (2002) em vídeo ganharam maior destaque em cada turma e, em ambas, no que diz respeito à reflexão sobre postura e ações docentes?

- Quais conceitos-chave foram destacados nos textos de Morin por cada uma das turmas e por ambas, sugerindo ações educacionais futuras?

- Que tipos de impactos causados pelas matérias de jornal foram manifestados pelos alunos de cada uma das turmas e, de ambas, nos depoimentos e debates?

- Que aspectos do filme NEHUM A MENOS ( 1999) catalizaram as atenções de cada turma e quais os que chamaram a atenção de ambas, gerando ,amifestações de pré-ocupação nos trabalhos dos grupos e debates?

O estudo teve como objeto duas categorias de manifestações dos sujeitos como alunos/atores singulares no contexto de cada turma, durante as atividades educacionais desenvolvidas em sala, com a contribuição da entrevista concedida por Morin (citada adiante) e do filme chinês anteriormente cidado e referenciado:

- manifestações verbais e escritas - apresentação de trabalhos, debates e produção de textos; e

- manifestações não-verbais - humor, aplausos, risos, exclamações, alegria, olhar (circunspecto, surpreso ou triste) e aceno (positivo ou negativo). 


\section{0 método de entrevista em pesquisa e como recurso pedagógico}

Uma entrevista de Morin (2002), em vídeo, concedida ao programa Milenium (TV GLOBO, 2001) um dos recursos aos quais se recorreu para abordar, nas disciplinas, as chamadas grandes questões humanas. Além disso, a entrevista foi simultaneamente empregada como método de pesquisa, tanto para apreender percepções (manifestadas verbalmente, por escrito e/ou oralmente) quanto para observar, como participante, as manifestações não-verbais sobre questões como democracia, liberdade, ensino e compreensão, ética e dialógica.

A categoria não-verbal interpretou a postura de Morin como a de "um complexo pensador da alegria [...] ainda que as misérias do mundo exijam circunspecção e críticas". (SILVA, 2001, p.23). O método de observação sistemática possibilitou apreender reações durante a exibição dos vídeos e o método de observação participante, durante os debates. Essa alternativa foi empregada para evitar que o silêncio se consumasse " por excesso de fala, a qual elimina a escuta"(Ibidem, p.26), para lembrar que "humor tem poder de síntese" e que "o riso surge como resposta epidérmica ao estímulo da inteligência [...] como provocação (Ibidem, p.22-23).

A entrevista escolhida é do tipo "não dirigida", seguindo a linha rogeriana de comunicação, o que não quer dizer "um encontro livre", improvisado. Ela "vai além da informação [...] dá ao homem, a palavra", é "democrática [...] pode ajudar a viver [...] provocando um desbloqueio, contribuindo para a auto-elucidação" (MORIN, 2001c, p.70-71) e, portanto, é adequada à proposta de ensino e de pesquisa explicitados.

\section{Expectativas da abordagem}

Com essa abordagem é possível esperar diferentes manifestações das turmas, não somente pelo fato de que não tiveram acesso, exatamente, aos mesmos recursos nem foram expostas às mesmas situações, como, por exemplo, o fato de que não houve palestra na região Norte. Essas diferentes manifestações também não decorrem apenas das diferenças culturais entre o Sudeste e o Norte, nem tampouco das diferenças individuais, das quais trataria a psicologia. Em especial, são esperadas manifestações diversas porque a fenomenologia, mesmo não se ocupando de nenhum desses importantes fatores, compreende-os no todo, pois leva em conta que a singularidade faz a diferença. Ela é esse algo próprio e único de cada ser humano que Merleau-Ponty (1971, p. 362) chamou de "corpo-próprio". É o poder de articulação com o qual cada um se exerce no mundo da vida, radicalizando a relação sujeito/objeto.

Por outro lado, são esperadas similaridades nas manifestações das turmas, porque são fenômenos humanos e pelo fato de que a singularidade é o que, simultaneamente, enreda os participantes de cada turma, ao mesmo tempo que os destaca em suas propriedades. Nesse sentido, este estudo vai apreender, interpretar e resumir, justamente, manifestações de diferenças únicas de cada uma das turmas e de similaridades entre elas; ou seja, "os diversos aspectos comuns a todos os participantes" de uma turma e de ambas, porque pode aproximar os resultados do que seja essencial a essas "experiências vividas". (MOREIRA, 2002, p.114).

A significância deste estudo está na descrição de uma abordagem à postura do professor, compartilhada com professores ex-alunos e com porfessores alunos, como possível fonte de reflexão teorica futura e prática de ensino, diante das chamadas grandes questões humanas.

Entretanto, aqui se alerta simultaneamente para o fato de o mundo estar "sempre ali, antes de qualquer reflexão, como algo inalienável" (MOREIRA, 2002, p.69) e para a situação em que essas experiências foram vividas, isto é, aquela na qual somos "o tecido com o mundo" que contribuimos para tecer, intencionalmente ou não.(FRAGA, 2003, p. 40, p.68). Esse é o caso do mundo vivido por cada uma das turmas de profesores-alunos em questão, experiência essa que não pode ser generalizada, mas aberta a novas discussões. 


\section{Pressupostos}

Como pressuposto pedagógico admitiu-se que o acesso dos alunos a diferentes tipos de recursos no ensinoaprendizagem possibilitaria a manifestação de fenômenos que lhes viessem à consciência e com os quais iriam se preocupar. Pressupôs-se, ainda, que as manifestações desses fenômenos seriam passíveis de apreensão neste estudo, porque aparências "não são ilusões vazias" (MOREIRA,2002,p.66) e a consciência é sempre consciência de algo (THIRY-CHERQUES, 2004, p.102). Além disso, tal acesso poderia favorecer o surgimento de uma visão intelectual do objeto, obtida intencionalmente, conforme viesse à consciência, manifestada pelas preocupações das turmas. Trata-se de uma busca da "experiência vivida do mundo, da vida, de todo dia”( MOREIRA, 2002, p. 67) dessas turmas.

\section{Compartilhamento, delimitação e população- alvo deste estudo}

O convívio com ex-alunos-professores inseridos nessa realidade complexa e particularmente injusta, familiarizados com a atitude fenomenológica (como busca de compartilhamento) motivou a abordagem adotada por este estudo quanto à postura docente. Isso decorre do fato de que ao conceber singularidades se interpenetrando no mundo, a ação de ensino-aprendizagem surge como possibilidade de cada um "assumir o que já é" (FRAGA,2003, p.140), ou seja, de retomar sua própria humanidade.

A tentativa de se aproximar do que é essencialmente desafiador à postura do professor, para povoar um horizonte comum e inclusivo da necessidade de diversidade de estilos próprios de aprendizagem e ensino visando à compreensão intelectual e a uma postura ética - levou às seguintes articulações na implementação das disciplinas:

- aprender com ex-alunos-professores;

- ensinar com ex-alunos-professores;

- aprender com alunos-professores;

- ensinar alunos-professores, para aprender a aprender e aprender a ser em comum, no ensino.

Consequientemente, vieram os primeiros aprendizados:

- situar-se no emaranhado dos debates sobre educação via matérias de quatro jornais de ampla circulação nas regiões Sul, Sudeste e Centro-Oeste foi uma sugestão de dois ex-alunos-professores para o plan ejamento das disciplinas. Habituados a compilar matérias para uso didático próprio, ambos ofereceram-nas às disciplinas;

- a retroalimentação de outros três ex-alunos-professores, reportando-se à época em que eram mestrandos, quando assistiram a trechos de clássicos do cinema - ficção inspirada em histórias de vida de professores e alunos - estimulou a incorporação desse recurso às disciplinas;

- os cinco ex-alunos-professores dispuseram-se a fazer palestras para os alunos-professores sobre a transversalidade da ética no currículo, andragogia e postura rogeriana, implicações weberianas na pesquisa em gestão educacional, diferenças culturais entre alunos e docentes, além de práticas e valores no ensino, temas que segundo Anísio Teixeira, implicam, em relação ao docente, uma postura de preocupação com o outro.

\section{Delimitando e descrevendo as duas experiências de ensino pesquisadas}

A disciplina Metodologia do Ensino, integrada ao MBA em Gestão Organizacional, envolveu uma turma, numa grande cidade, capital de estado da região Sudeste. A disciplina Manifestações e sentido socioeducacional brasileiro, integrada ao curso MBA em Gestão Escolar, foi ministrada numa cidade com cerca de 1,5 milhão de habitantes, capital de um estado da região Norte. 
Na cidade do Sudeste, a população-alvo constitui-se de profissionais experientes em áreas técnicas como finanças, informática, projetos e auditoria, todos docentes em educação continuada nas respectivas áreas de conhecimento. O nível de escolaridade variou entre a graduação e candidatos a doutorado, passando por aqueles que estão em cursos de aperfeiçoamento, por mestrandos e mestres.

Na cidade do Norte, a população-alvo era constituída de professores de escolas públicas de ensino fundamental e médio, com tempo de serviço variando entre 17 e 25 anos. Quanto à escolaridade, além da graduação, cursos de aperfeiçoamento, especialização e candidatos ao mestrado.

Os objetivos de ensino das duas disciplinas e o foco deste estudo estavam concentrados na postura docente, reconhecendo a complexidade do contexto socioeconômico brasileiro, além dos objetivos relativos às especificidades de cada curso. Daí, o foco em questões educacionais locais e globais como democracia, inclusão social, cidadania e ética, na linha do referencial teórico.

Os objetivos específicos das disciplinas incluíram observar: experimentar e analisar as possibilidades dos temas abordados com o propósito de incentivar os participantes a lidar com recursos didáticos e pedagógicos diversos, tais como matérias de jornal, palestras, capítulos de livros, imagens e vídeos bem como a se exporem a simuladas situações-problema, como produção escrita em grupo, escolha de temas em grupo, para debates intra e intergrupais e apresentação de trabalhos em grupo à turma, visando ao fortalecimento de uma postura docente disposta a enfrentar os desafios do contexto descrito na introdução

\section{Respondendo às questões do estudo}

\section{Impactos do emprego da entrevista de Morin (2002) em vídeo}

\section{Preocupações da turma de professores em educação continuada}

Contribuir para ampliar o poder de agregação social para além do lúdico binômio carnaval/futebol, a partir do exercício democrático e dialógico nas relações em aula. Rever a postura tradicionalista diante do "erro" (MORIN, 2001b, p.151), não para a permissividade, mas para o aprendizado de vida.

\section{Preocupações da turma de professores do ensino fundamental e médio}

Ensinar diferenças culturais, tolerância e consciência planetátia desde a infância, nas escolas.. Empenhar-se por relações mais igualitárias e participativas com os adolescentes, estimulando a autodisciplina. Reportando a Fraga (2003, p.16), indicam expectativas futuras sobre o desenvolvimento do "agente que se reconhece como responsável pela orientação ética de suas ações”. Assumir e contribuir para uma postura ecológica global. A turma revela orgulho pelos projetos ambientais locais.

As duas turmas manifestaram disposição para refletir sobre o conceito de "terra pátria" nos sentidos ecológico e ético, visando a uma educação global, mais humana, de respeito à diversidade de interesses e de idéias.Ensinar a democracia acolhendo as regras do jogo democrático.

\section{Resultados da observação sistemática: manifestações da turma do Norte à entrevista de Morin}

Pediu para rever a entrevista no intervalo das aulas e tomou a iniciativa de controlar os ruídos externos - pois entendeu que atrapalhava sua concentração - para entender o conceito de "horizonte husserliano", conforme abordado por Fraga (2003, p.44), devido à relação estabelecida com a "antropo-ética" de Morin, com a expectativa de inclusão dos diferentes. Além disso,engajou-se em troca de depoimentos e elaboração de resumos em grupos, sobre o tema, para apresentação aos colegas, permanecendo em participação além do horário exigido. 


\section{Conceitos- chave destacados nos sete saberes para a educação do futuro}

\section{Turma do Sudeste}

A democracia necessita ao mesmo tempo de conflitos de idéias e de opiniões, que lhe conferem sua vitalidade e produtividade [...] [para que possa] se expandir em obediência às regras democráticas que regulam os antagonismos, substituindo as lutas físicas pelas lutas de idéias que determinam, por meio de debates e das eleições, o vencedor provisório das idéias em conflito, aquele que tem, em troca, a responsabilidade de prestar contas da aplicação de suas idéias. (MORIN, 2001d, p.108)

Foram registradas verbalizações sobre o reconhecimento do desafio que essa proposta representa para cada professor em sala de aula, sobre suas própria atuação, tendo em vista o tradicionalismo da sociedade que estimula o autoritarismo de quem detém algum poder, o conformismo e a submissão ou, em contraste, reações que vão da indignação ao laisser-faire num continuum. Desafio, ainda, em sala de aula de educação continuada, em ambiente por vezes hostil, devido à concepção de aluno como cliente que espera ser agradado, em vez de estimulado e exigido.

\section{Turma no Norte}

A "antropo-ética", resumida como "assumir a condição humana indivíduo/sociedade/espécie, [...] assumir a humanidade em nós mesmos [...] assumir o destino humano". (MORIN, 2001d, p.104).

Reportando ao horizonte husserliano e "à verdade polissêmica" (FRAGA, 2003, p.79), construir uma democracia na qual os "afetados pelas instituições sociais compartilhem da produção das mesmas e de sua administração" (Ibidem, p.19), e, nesse sentido, que os professores administradores enfrentem o desafio da autogestão

\section{Reações às matérias de jornal}

As discussões foram acirradas e, nesse sentido, novas pesquisas possibilitariam avaliar o quanto os alunos em educação continuada estão conscientes das grandes questões educacionais apontadas nas matérias.

O quadro 1 apresenta os resultados da observação sistemática dos debates em que os grupos discutiram livremente suas posições. As matérias foram renomeadas na coluna da esquerda conforme foram apresentadas pelos grupos, ora da turma da cidade da região Sudeste, ora da cidade da região Norte. As demais colunas revelam uma escala das reações de cada uma das turmas ou de ambas, indo da veemência à simples constatação. 
Quadro 1 - Reação das turmas diante das matérias de jornal: da mais veemente à mera constatação

\begin{tabular}{|c|c|c|c|c|c|}
\hline \multirow{2}{*}{ Matérias de jornal renomeadas } & \multicolumn{2}{|c|}{ Reação } & \multicolumn{3}{|c|}{ Constatação do(a) } \\
\hline & Indignação & Polêmica & Problema & Falta & Situação \\
\hline Desigualdades desde o nascimento, no Brasil & TS/TN & & & & \\
\hline Desvantagens da mulher desde a infância & & & TN & & \\
\hline Meninos brasileiros evadem, para trabalhar & & & TN & & \\
\hline Desigualdades no Brasil - Unicef & TS/TN & & & & \\
\hline Mundo "sem educação" & TS & & & & \\
\hline Desigualdade e futuro dos brasileiros & TS/TN & & & & \\
\hline Escolaridade da mãe importa & & & $\mathbf{T N}$ & & \\
\hline Cursos criados onde o MEC indicar & & TS & & & \\
\hline Universidade pública - quem deve pagar? & & TS/TN & & & \\
\hline Ensino profissionalizante no Brasil & & TS & & & \\
\hline Programa Nacional de Cotas & & TS/TN & & & \\
\hline Iniciação científica é possível? & & & & & TN \\
\hline Ensino superior, trabalho e competências & & & TS/TN & & \\
\hline Educar para a vida & & & & $\mathrm{TS} / \mathrm{TN}$ & \\
\hline
\end{tabular}

Fonte própria.

TS = turma da cidade do Sudeste

$\mathrm{TN}=$ turma da cidade do Norte

Manifestações da turma do Sudeste

Depoimentos dos grupos

Há dados obtidos em estudos internacionais que deveriam ser tomados no país como "alarmantes". Porém, parece haver um crônico descaso diante de "desempenhos lamentáveis do ensino, em especial de português e matemática". "Nós mesmos precisamos fazer uma leitura crítica de nosso desconhecimento dessa situação nacional., uma realidade na qual estamos inseridos e sobre a qual nos surpreendemos a partir de relatórios como os da Unicef".

\section{Manifestações da turma do Norte}

Depoimentos dos grupos

Nosso sentimento é que

por mais que trabalhemos, somos sempre devedores às crianças no ensino fundamental. [...] Não é só uma questão de falta de condições de estudo, é de falta de condições de vida o que faz a questão da educação fundamental ser tão complexa e desafiadora. [...] De qualquer forma, continuamos a fazer a nossa parte, mas as matérias mostram que está longe de ser suficiente.

\section{Manifestações comuns às duas turmas}

As matérias discutidas despertaram mais "denúncias e críticas do que soluções". São "problemas muito difíceis de enfrentar", mas só constatação não resolve. Entretanto, parece que vários problemas só são constatados no exterior. Há muita "necessidade de pesquisa em educação", mas o investimento é mínimo, ou esse seria um exemplo de "disputa interna ao sistema sobre verbas para ciência e tecnologia, em detrimento da educação?" "A questão das cotas" talvez não seja um equívoco, mas "parece", pelo menos, "incompleta". 


\section{Reações verbais e não- verbais das turmas diante de situações, imagens, mensagens e diálogos revelados pelo filme chinês NENHUM A MENOS ( 1999).}

\section{Turma da cidade do Norte}

\section{Situações}

Os chamados professores leigos, situação vivida pela professora substituta adolescente, carente de ensino, como ocorre no interior do Brasil: aceno negativo, olhar triste.

Imagens

Semelhanças entre a paisagem da região chinesa (vegetação e terra) e a do nordeste brasileiro, inclusive, com a presença de jegues: exclamações de surpresa.

\section{Mensagens não verbais}

Brincadeiras, rebeldia, espontaneidade das crianças interpretadas como reações universais: humor, risos. Problemas na remuneração do professor e necessidade de reivindicar direitos supostamente garantidos: aceno negativo, indignação.

\section{Diálogos}

Político local em relação ao menino pobre, buscando certa cooptação: aceno negativo, olhar de indignação. A professora com a mãe (muito pobre e doente ) do aluno que deixou a escola pela "aventura" da cidade, em busca de sobrevivência da família: olhar triste. O diálogo da professora inexperiente com a turma de alunos, das mais diversas faixas etárias, e o método recitativo de ensino: riso, olhar circunspecto.

\section{Turma da cidade do Sudeste}

\section{Situações}

Perigos enfrentados pelas crianças de rua, a luta por abrigo e alimento, o risco de ceder ao diante da necessidade de alimento: olhar circunspecto. A percepção do problema pela comerciante e a solução racional, oferecendo alimento e trabalho, para não afetar a clientela e não abandonar o menino: humor, aceno positivo e aceno negativo.

\section{Imagens}

A improvisação da professorinha diante da necessidade de ensinar uma canção à turma, no pátio da escola, diante da bandeira hasteada: risos, olhar de surpresa.

\section{Mensagens não verbais}

A organização funcional da escola com parcos recursos, para estudar e viver em dois ambientes: sala de aula e dormitório masculino, sala do professor e dormitório feminino. Aproveitamento máximo de objetos e móveis precários com disciplina e tenacidade: olhar circunspecto, olhar triste.

\section{Diálogos}

Negociação entre professor e prefeito - diferentes responsabilidades diante da mesma realidade adversa: olhar circunspecto. A professorinha e a menina da cidade, valores contrastantes, tentativa frustrada de compreensão recíproca: olhar circunspecto.

A professorinha em busca de acesso à mídia, o poder concreto da mídia em contraste com a ingenuidade dos protagonistas: exclamações de indignação, olhar circunspecto, olhar triste. 


\section{Ambas as turmas}

\section{Situações}

Iniciativa, liderança e poder de articulação da professorinha com a turma diante da responsabilidade pelo aluno ausente: olhar circunspecto.

O trabalho com crianças na olaria para conseguir fundos e procurar o aluno. A determinação das crianças em buscar recursos e o método recitativo transformado em participativo, com base em cálculos matemáticos, para administrar os problemas concretos da vida dos alunos e da professora leiga, personagens do referido filme, em decorrência do compromisso assumido por ela quanto à mantê-los unidos: olhar alegre, aplausos, riso, aceno positivo.

\section{Imagens}

O sabor do primeiro gole de refrigerante: olhar alegre, riso, aceno positivo.

A emoção do menino que evadiu e da professora que o procurava na "telinha de achados e perdidos" da TV: olhar circunspecto, triste.

A criatividade inusitada do relógio solar que deveria definir o encerramento da aula: olhar circunspecto, risos.

A emoção de escrever ou desenhar a cores: olhar alegre, riso.

\section{Mensagens}

Respeito da professora substituta pelo professor, o zelo pelo recurso didático: o giz. O ambíguo sentimento da professora: extrema responsabilidade pelo aluno e a expectativa de remuneração pelas aulas: olhar circunspecto. $\mathrm{O}$ futuro sonhado pelo aluno que retorna à escola para concluir seus estudos, conseguir um emprego e presentear sua dedicada professora com o que considerava o mais belo dos presente, flores: olhar alegre, risos. Depoimento circunspeto do menino, ao retornar, sobre a humilhação de pedir comida na soliddão ida cidade: olhar circunspecto.

\section{Diálogos}

\section{Entre professores}

"Tudo em torno do giz", condição essencial para ministrar aulas, conferi-los e utilizá-los com absoluta parcimônia: olhar circunspecto. Diálogos entre a professorinha e seus alunos no momento de "fartura com giz colorido', com o propósito de aguardar o retorno do professor, dando, no máximo, uma barra de giz para cada aluno escrever um só palavra a cores, na mais completa austeridade e alegria: olhar circunspecto, riso, lágrimas.

Figura 1 - Ideogramas escritos pelos alunos, com alegria e a cores, no quadro-de-giz**

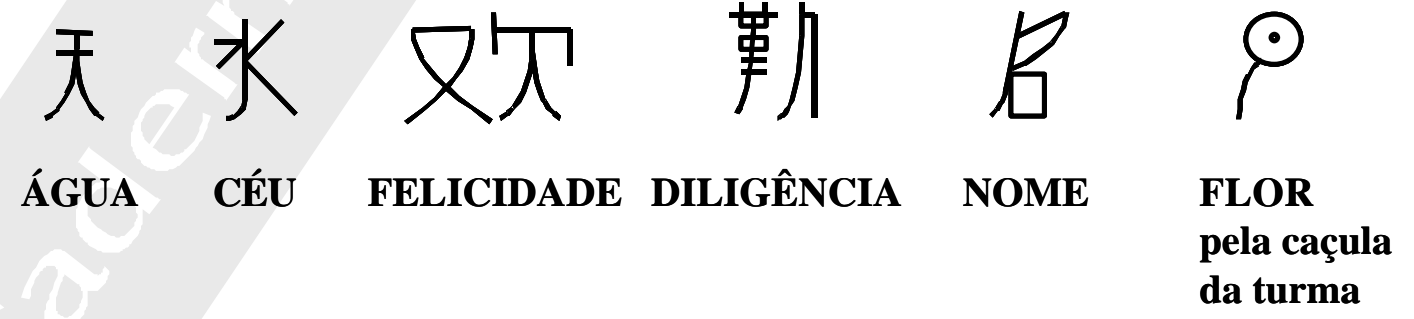

Fonte própria.

*O nome escrito no quadro pelo aluno que retornou foi o da protagonista, a professora Wei. 


\section{Resultados da observação sistemática}

\section{Turma do Sudeste: o filme chinês e as palestras.}

A turma se organizou para rever o filme (NENHUM A MENOS, 1999), inclusive, com colegas que não eram alunos da turma e/ou com seus familiares profissionais da educação e em atividade docente.

Em continuidade, a turma engajou-se na discussão de questões de natureza ética com os palestrantes, incluindo o tema possibilidades da transversalidade da Ética em Educação Continuada. Além disso, manifestou sintonia com a não-diretividade rogeriana como possibilidade de autogestão e andragogia, no sentido da autocrítica, aplicando os conceitos a um continuum de postura docente, partindo do autoritarismo ao laisser-faire. Analisou criticamente o referencial teórico da burocracia weberiana e a rotinização no ensino como corrosão da motivação de professores e alunos. Os valores, nas práticas docentes, foram foco recorrente nas discussões sobre a postura do professor.

\section{0 que foi possível considerar ao final deste estudo.}

A evidente avidez da turma do Sudeste por conteúdos especialmente didáticos, mas também pedagógicos, e a expectativa por conteúdos específicos, previstos em metodologia do ensino (como avaliação de aprendizagem), não interferiu na disposição para tratar das chamadas grandes questões humanas. Pelo contrário, os problemas mais pontuais, relativos a conteúdos específicos, foram sendo passo a passo aprofundados e ampliados pelas relações estabelecidas entre estes e a postura do professor diante de questões como democracia, cidadania e compartilhamento.

A experiência da turma do Norte em lidar com situações mais estruturadas em aula - devido à atuação no ensino regular - também não interferiu na disposição para estudar e debater as chamadas grandes questões, das quais começaram a surgir vestígios, nos debates que enfocavam relações com alunos, pais, colegas professores e administradores nas escolas de primeiro e segundo grau. A questão da inclusão e da cidadania reportou à necessidade de se ter preocupação com o outro e do exercício da tolerância para a eqüidade como norteadores da postura docente.

As matérias de jornal geraram debates acalorados e tanto fizeram aparecer as preferências singulares das duas turmas, diante de certos tópicos, quanto contribuíram para que se manifestassem percepções comuns em relação a alguns problemas, ainda que nem sempre similares no que diz respeito às alternativas de solução.

As manifestações relacionadas aos recursos didáticos empregados e às situações pedagógicas intencionadas, possibilitaram trocas de percepções, de aspirações, de preocupações e de expectativas sobre comprometimento com ações futuras, relacionadas a uma postura local e, simultaneamente, global dos docentes. Em continuidade, a observação sistemática e a observação participante, visando ampliar o espectro das manifestações das turmas, extrapolou a escrita e a verbalização, em busca de sinais não-verbais. Desse modo, favoreceu a apreensão de indícios e de indicadores de reações e iniciativas, diante de conteúdos e imagens apresentados nos vídeos. Nesse ponto, é possível concluir pela adequação dos recursos quanto aos objetivos pedagógicos, bem como da metodologia que incluiu a linguagem corporal.

Por outro lado, justamente, a riqueza de manifestações a serem resumidas pode ter se constituído em limitações deste estudo, mesmo que a descrição realizada tenha tentado minimizar.

As chaves das manifestações que se revelaram comuns às turmas aparecem relacionadas à compreensão da postura de Morin que, ao reconhecer cientificamente a complexidade das sociedades e ao expressar-se sobre o 
desafio de construir a democracia plena, parece ter exercido um grande apelo à critica e à autocrítica que emergiu em depoimentos e debates nas duas turmas.

As palestras foram motivo de satisfação para todos os participantes, deixando como saldo a reflexão sobre:

- a ênfase na postura ética do docente;

- equilíbrio entre gestão e autogestão, critica e autocrítica e a autonomia rogeriana;

- a leitura crítica da postura weberiana;

- as diferenças culturais e subculturais de docentes e alunos, diferentes estilos de comunicação no ensino/aprendizagem; e

- a necessidade de vínculo entre discurso e ação na postura docente.

A comunicação não-verbal de cada palestrante, diante dos agradecimentos dos professores-alunos, revelou gratificação pessoal, com a retribuição de gestos de afeto, aplausos, sorrisos, palavras por vezes emocionadas ou com momentos de eloquente silêncio compartilhados com da turma do Sudeste.

O filme "NENHUM A MENOS" (1999) iluminou a questão do professor leigo, encarnando pela professora adolescente. Revelou uma realidade similar à brasileira o que emocionou, particularmente, os alunosprofessores em educação continuada e reforç ou empatia nos professores do ensino fundamental e do ensino médio.

As manifestações da turma do Sudeste indicaram que as mensagens do referido filme aproximaram mais os professores-alunos - cuja cultura é urbana - da realidade do interior do Brasil, a apartir das similaridades entre a realidade rural do país e aquela vivida pela professora Wei. Além disso, segundo depoimentos, a inexperiência e a ingenuidade da protagonista, em contraste com sua tenacidade, responsabilidade e criatividade, reforçou o respeito da turma de professores do ensino básico em relação a "esses anônimos heróis brasileiros e globais", os professores leigos.

É possível dizer que o filme (NENHUM A MENOS,1999) desempenhou o papel de ponte entre a vivência da turma da grande cidade do Sudeste e a realidade do professor leigo das áreas rurais do país. Além disso, também foi uma ponte entre a vivência da turma da cidade do Norte e a realidade das crianças de rua das grandes capitais, em sua dramática busca por trabalho ao abandonarem a escola.

Duas questões singularizaram cada uma das turmas, cujos depoimentos sugerem pesquisas futuras sobre a postura docente: na turma do Sudeste, a questão do aluno em educação continuada, percebido como "cliente a ser agradado" e, na turma do Norte, a preocupação em "ensinar" democracia relacionada ao meio ambiente e, nesse sentido, o impacto do orgulho $\mathrm{X}$ a necessidade em relação aos projetos ambientais locais manifestou-se em falas contundentes. 


\section{Referências}

BOULOS, M. A USP abre seu coração. Folha de São Paulo, 21 ago. 2006. Opinião.

CARNEIRO, R. Aprender e educar no século XI. Revista Brasileira de Política e Administração da Educação, Rio de Janeiro, v.21, n.1/1, p.1131, jan./dez. 2005.

FRAGA, V. F. Gestão pela formação humana: uma abordagem fenomenológica. Rio de Janeiro: Impetus, 2003.

GONÇALVES, H. M. Movere, docere, deletare: argumentos sobre a ética. 2005. Tese (Doutorado em Educação) - Universidade Federal do Rio de Janeiro (UFRJ), Rio de Janeiro, 2005.

JARDILINO, J. R. L. A questão do financiamento da universidade brasileira: setores público e privado numa eqüidade de sistemas. Revista Brasileira de Política e Administração da Educação, Piracicaba, v.19, n.2, p.195-212, jul./dez. 2003.

JARDIM , M. A. A importância da ética na educação: a mais valia ricoeriana. Revista Brasileira de Política e Administração da Educação, Piracicaba, v.20, n.2, p.59-81, jul./dez. 2004.

M OREIRA,D.A. Ométodo fenomenológico na pesquisa. São Paulo: Pioneira, 2002.

MORIN, E. O método. 4. As idéias. Tradução: Juremir Machado da Silva. Porto Alegre: Sulina, 1998.

. As duas globalizações. In: SILVA, J. M.; M ORIN, E. As duas globalizações: complexidade e comunicação, uma pedagogia do presente. Porto Alegre: Meridional; Edpuc (RS), 2001a.

Ciência com consciência. Tradução: Maria D. Alexandre e Maria Alice Sampaio Dória. Rio de Janeiro: Bertrand Brasil, 2001b.

Da entrevista do vídeo e na televisão. In: SILVA, J. M.; MORIN, E. As duas globalizações: complexidade e comunicação, uma pedagogia do presente. Porto Alegre: Meridional; Edpuc (RS), 2001c.

. Os sete saberes necessários à educação do futuro. Tradução: Catarina Eleonora F. da Silva e Jeanne Sawaya. São Paulo: Cortez/Unesco, 2001d.

. Entrevista ao Milenium. In: CONGRESSO INTERNACIONAL DE EDUCAÇÃo E CULTURA. São Paulo: Sesc; Rede Globo de Televisão Elisabeth Carvalho, 2002.

NERI, M. Social credit base on educational targets and performance. In: INTERNATIONAL SEM INAR ON QUALITY OF EDUCATION, 2005. Rio de Janeiro: EPGE/FGV, 2005.

NENHUM A MENOS (Existe um sol no céu). [S.I.]: Guangxi Film Studio \& Beijing New Pictures, 1999.

PAZETO, A. E. Universidade e diversidade: descaminhos do modelo universitário brasileiro. Revista Brasileira de Política e Administração da Educação, São Bernardo do Campo, v.18, n.1, p.81-95, jan./jun. 2002.

RODRIGUES, N. As aventuras da razão educativa na construção do modelo universitário brasileiro. Revista Brasileira de Política e Administração da Educação, São Bernardo do Campo, v.18, n.1, p.11-23, jan./jun. 2002.

SILVA, J. M. Em busca da complexidade esquecida II. In: SILVA, J. M.; MORIN, E. As duas globalizações: complexidade e comunicação, uma pedagogia do presente. Porto Alegre: Meridional; Edpuc (RS), 2001

THYRY - CHERQUES. Programa para aplicação às pesquisas em ciências de gestão e um método de caráter fenomenológico. In: VIEIRA, M. M.; ZOUAIN, D. M. (Org.). Pesquisa qualitativa em administração. Rio de Janeiro: FGV, 2004. 